\title{
Water repellent soils: the case for unsaturated soil mechanics
}

\author{
Christopher Beckett ${ }^{1}$, , Andy Fourie ${ }^{1}$ and David Toll ${ }^{2}$ \\ ${ }^{1}$ The University of Western Australia, Perth, WA. \\ ${ }^{2}$ Durham University, Durham , UK.
}

\begin{abstract}
Water repellent (or "hydrophobic" or "non-wetting") soils have been studied by soil scientists for well over a century. These soils are typified by poor water infiltration, which leads to increased soil erosion and poor crop growth. However, the importance of water repellence on determining soil properties is now becoming recognised by geotechnical engineers. Water repellent soils may, for example, offer novel solutions for the design of cover systems overlying municipal or mine waste storage facilities. However, investigations into factors affecting their mechanical properties have only recently been initiated. This purpose of this paper is to introduce geotechnical engineers to the concept of water repellent soils and to discuss how their properties can be evaluated under an unsaturated soils framework. Scenarios in which water repellent properties might be relevant in geotechnical applications are presented and methods to quantify these properties in the laboratory and in the field examined.
\end{abstract}

\section{Introduction}

Soil water repellency (also known as "hydrophobicity" or "soil non-wetting") has been a concern of soil scientists for well over a century. Water repellency is now recognised to be a worldwide phenomenon affecting soils under both natural and agricultural vegetation [1]. For example, in Western Australia, it is estimated that as many as 7 million hectares of agricultural land are affected by or are under risk of water repellency. Expressed another way, lost production on this land due to water repellence alone is of the order of AUD250-300 million per annum [2].

Soil water repellency develops due to a variety of causes. The most common is the deposition of organic matter derived from decaying plants, however secretion of plant oils, growth of humic substances and treatment with wastewater ("grey water") are also strong contributors [1,3]. Excessive drying, for example as occurs during wildfire events or during the summer periods in arid regions also give rise to short-term water repellency [4]. Water repellency results in poor infiltration and increased runoff and erosion during rainfall or irrigation, which accelerates pesticide and nutrient transport to groundwater and reduces the efficiency of irrigation strategies [5].

Water repellency has generally been dismissed by geotechnical engineers due to the common assumption that soils are always wettable [6]. However, the effects of water repellency are now becoming recognised as being important in governing soil infiltration and stability [7,8]. The use of vegetated solutions in geotechnical design (e.g. slope stability, waste site rehabilitation) is also becoming more popular [9-11]. The effects of water repellency on such systems must therefore be examined.

This paper discusses the effects of water repellency on the properties of unsaturated soils and presents a case for water repellency to be considered by geotechnical engineers. Effects of water repellent behaviour on soil retention properties on the micro and macro scales are examined. Examples of consequences of water repellency on geotechnical design are then presented and methods to quantify water repellency in the laboratory and in the field briefly discussed.

\section{Effect of water repellency on soil water retention}

\subsection{Microscopic level}

A water-repellent surface is defined as one whose contact angle $(\theta)$ is $\geq 90^{\circ}$ [12]. The contact angle is fundamental to unsaturated soil mechanics and can be linked to suction through the familiar capillary tube analogy of the Young-Laplace equation (Equation 1), which gives the matric suction $\left(\psi_{m}\right)$ arising due to a curved air-water interface

$$
\psi_{m}=\frac{2 \gamma}{r}, r=\frac{R}{\cos \theta}
$$

where $\gamma$ is the air-water surface tension, $r$ is the radius of the concave meniscus and $R$ is the radius of the capillary tube (a pore size analogue).

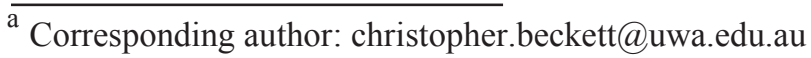



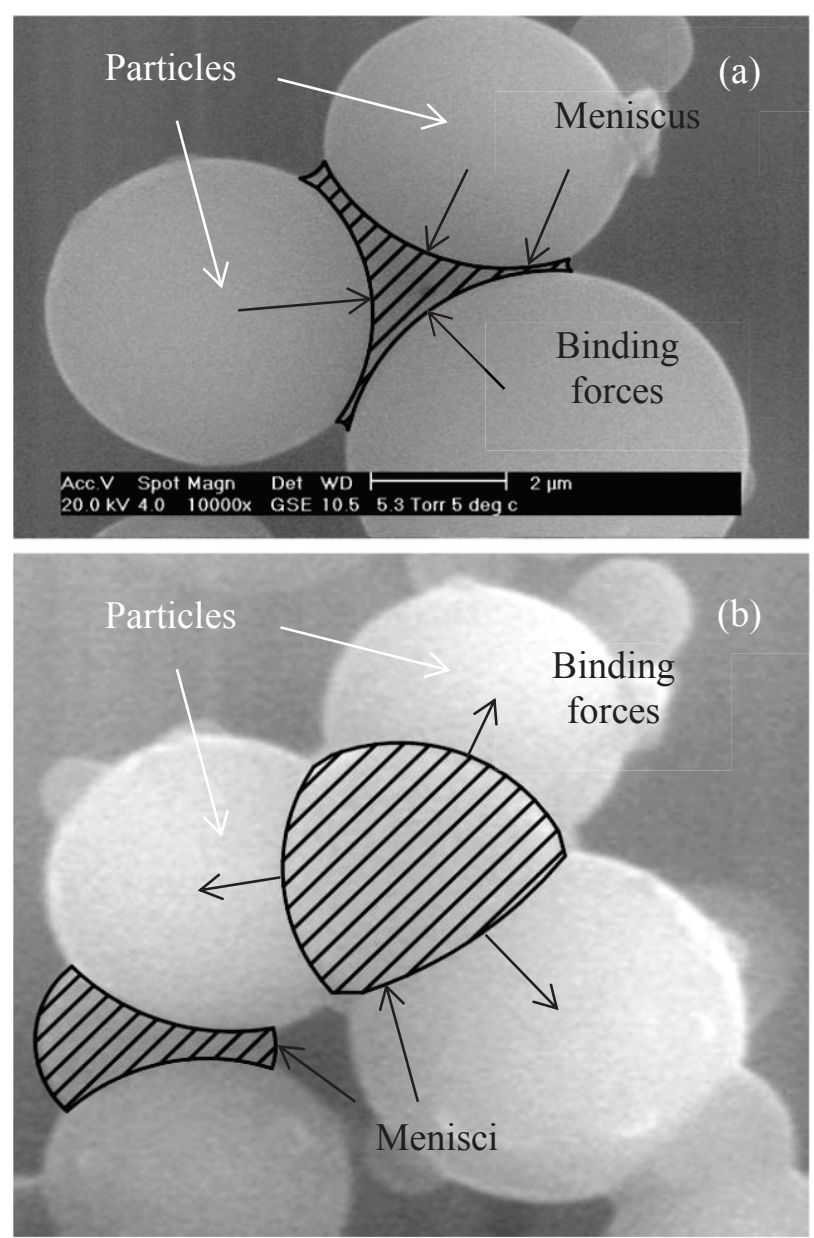

Figure 1. ESEM micrographs of water menisci between: a) hydrophilic particles; b) the same particles in a water repellent state. Magnification as per (a). Modified from [13].

An ESEM micrograph of concave menisci between hydrophilic silica spheres (a simulated soil) is shown in Figure 1a. By Equation 1, the concave shape gives rise to positive suction (i.e. negative pressure), acting to bind the particles together. However, for water repellent soils, $\theta>90^{\circ}$ gives rise to convex menisci, as shown in Figure 1b. In a highly simplified sense (as the meniscus geometry is not spherical), by Equation 1 suction in these menisci would be expected to be negative, i.e. positive water pressures would be generated despite saturation being $<1$. Geotechnical engineers are already familiar with the effect of changes in contact angle affecting suction due to suction hysteresis; advancing or retreating contact angles during wetting or drying (respectively) give rise to significantly different suction values for a given degree of saturation [14]. It is reasonable, then, that this effect might be heightened in water repellent soils, so that suction may enter a negative domain (e.g. as suggested by [15] and [16] for different liquid bridge or meniscus configurations). The concept of negative 'suctions', however, requires further investigation to be validated.

\subsection{Macroscopic level}

Retention properties of hydrophilic and water-repellent soils were investigated by [17]. A granular soil was artificially hydrophobised by treating with dichlorodimethylsilane (a process called "silanisation"). Samples were prepared at an initially-wet state close to saturation and suction was applied via a hanging column.

Results found by [17] are summarised in Figure 2, where $S_{r}$ is the degree of saturation. A reduction in air entry value (AEV) was found for the water repellent material, and retention curves for the water repellent and hydrophilic soils differed significantly in the $\mathrm{AEV}<\psi<$ residual suction range. Notably, hydrophilic and water-repellent retention curves were similar in the low $(<\mathrm{AEV})$ and high (greater than residual) suction ranges. Similar results were found by [16] and [18]; lower gravimetric water contents were found for hydrophobised granular soils than for the same soils in a hydrophilic condition for a given suction.

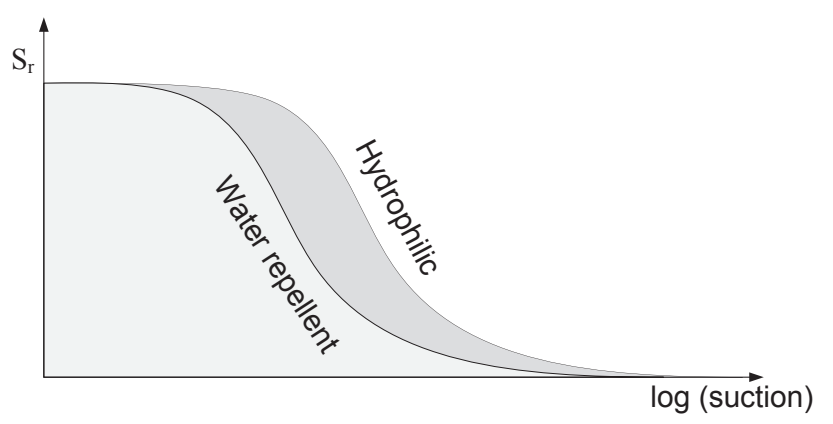

Figure 2. Simplified drying soil water retention curves for hydrophilic and water repellent soils tested in [16].

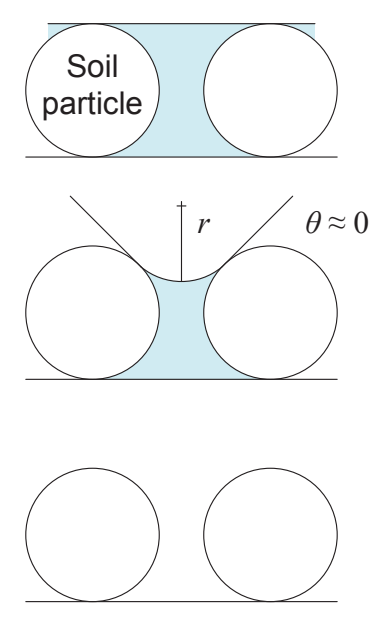

Hydrophilic case

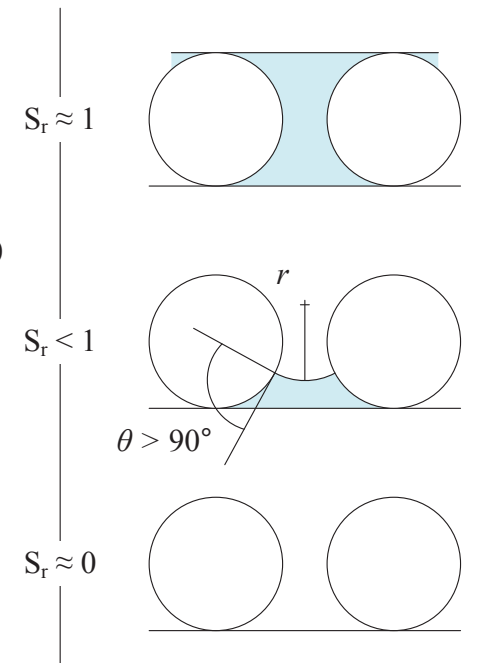

Water repellent case
Figure 3. Desaturation of hydrophilic (left) and water repellent (right) granular soil. Shaded region represents pore water.

Possible desaturation mechanisms for a hydrophilic and water repellent granular soil are shown schematically in Figure 3. For the hydrophilic and water repellent soil, similar pore water volumes are likely to be present at high and low degrees of saturation. However, higher contact angles in the water repellent soil result in lower pore water volumes in the intermediate suction range for a given suction value (i.e. given value of $r$ in Equation 1). The same result can be obtained by changing $\theta$ in 
Equation 1; higher values of $\theta$ (restricted to $\theta \leq 90^{\circ}$, for which Equation 1 is defined) give smaller $R$ values for given values of $r$, demonstrating smaller stored volume. It should be noted, however, that this is not a reduction in actual pore size, merely the storage capacity of given pore sizes [19].

Notably, tested soils in [16] to [18] displayed positive suctions. Soils in [17] were not tested in wetting, which is more likely to produce higher contact angles. Samples in [16] and [18] were tested in both drying and wetting. However, hydrophobising reagents were selected to mimic natural water repellent substances, whose contact angles were either $<90$ degrees or reduced from $\theta=90^{\circ}$ in the presence of water [4]. The behaviour of naturally water repellent soils is discussed later in this paper. It is therefore not possible to conclusively say from these results whether negative 'suctions' may develop in macroscopic cases. However, it is evident that water repellency has a significant effect on retention properties.

\section{Example effects of water repellency on soil behaviour}

\subsection{Shear strength}

It is well known that the mechanical properties of unsaturated soils are intimately linked to changes in soil suction. Changes in soil water retention on the advent of water repellency will therefore also result in a change in mechanical behaviour.

[7] examined the shear strengths of glass beads (an idealised granular soil) under hydrophilic and water repellent conditions. The hydrophobisation process used was similar to that used in [16] and produced a permanently water repellent material. Contact angles for the two materials were 10 and $100^{\circ}$ respectively.

Results from [7] for direct shear tests on hydrophilic and water repellent material at 0 and 5\% saturation are given in Table 1. Although tested on a relatively narrow normal stress range, water repellency resulted in a reduction in $\phi^{\prime}$ and $c$ at both tested $S_{r}$ values. Unfortunately, retention properties for the materials were not determined, nor were suction measurements made during testing. It is therefore possible that both suction and $S_{r}$ changed during the test due to sample volume changes [20]. However, a decrease in strength between the hydrophilic and water repellent samples at a nominally-constant value of $S_{r}$ is consistent with results summarised in Figure 2; for a given value of $S_{r}$, a lower suction, and so a lower strength, would be expected for the water repellent material.

[21] performed a similar testing program to [7] using a natural, uniform sand. Retention properties for the hydrophilic sand were determined and direct shear tests performed on hydrophilic and hydrophobised (again, using silanisation) samples under suction-monitored conditions. Results are presented in Table 2. As for [7], [21] found a reduction in $\phi^{\prime}$ between the hydrophilic and water repellent material. That little change was found between air-dry and moist samples was likely due to a combination of the low suction values and high normal stresses present during the test. Notably, little difference was found between the dilative behaviour of hydrophilic samples across the tested normal stress range (all samples dilated), however water repellent sample behaviour differed significantly; samples dilated at low $S_{r}\left(S_{r}<\right.$ 0.4 ) but contracted at higher $S_{r}$. Such changes could have been due to slight differences in initial sample void ratio.

Table 1. Summary of shear strength results reported in [7]. Note that $c$ is suction dependent (i.e. values have not been related to zero suction).

\begin{tabular}{|c|c|c|c|c|}
\hline $\begin{array}{c}S_{r} \\
(\%)\end{array}$ & Condition & $\begin{array}{c}\phi^{\prime} \\
(\text { degrees })\end{array}$ & $\begin{array}{c}\mathrm{c} \\
(\mathrm{kPa})\end{array}$ & $\begin{array}{c}\text { Normal stress } \\
\text { range }(\mathrm{kPa})\end{array}$ \\
\hline \multirow{2}{*}{0} & Hydrophilic & 29.3 & 2.83 & $1-20$ \\
\cline { 2 - 5 } & $\begin{array}{c}\text { Water } \\
\text { repellent }\end{array}$ & 10.6 & 0.73 & $1-20$ \\
\hline \multirow{2}{*}{5} & Hydrophilic & 40.4 & 2.28 & $1-10$ \\
\cline { 2 - 5 } & $\begin{array}{c}\text { Water } \\
\text { repellent }\end{array}$ & 28.9 & 0.73 & $1-10$ \\
\hline
\end{tabular}

Table 2. Shear strength results reported in [21]. a hydrophilic suction values.

\begin{tabular}{|c|c|c|c|c|c|}
\hline $\begin{array}{c}S_{r} \\
(\%)\end{array}$ & $\begin{array}{c}\text { Suction } \\
\text { range } \\
(\mathrm{kPa})\end{array}$ & Condition & $\begin{array}{c}\phi^{\prime} \\
(\text { degrees })\end{array}$ & $\begin{array}{c}\mathrm{c} \\
(\mathrm{kPa})\end{array}$ & $\begin{array}{c}\text { Normal } \\
\text { stress } \\
\text { range } \\
(\mathrm{kPa})\end{array}$ \\
\hline $\begin{array}{c}\text { Air } \\
\text { dry }\end{array}$ & $\mathrm{n} / \mathrm{a}$ & Hydrophilic & 36.1 & 0 & $20-80$ \\
\hline $\begin{array}{c}\text { Air } \\
\text { dry }\end{array}$ & $\mathrm{n} / \mathrm{a}$ & $\begin{array}{c}\text { Water } \\
\text { repellent }\end{array}$ & 27.9 & 0 & $20-80$ \\
\hline $\begin{array}{c}0.36- \\
0.64\end{array}$ & $2-3$ & Hydrophilic & 36.1 & 0 & 50 \\
\hline $\begin{array}{c}0.27- \\
0.62\end{array}$ & $2-3^{\mathrm{a}}$ & $\begin{array}{c}\text { Water } \\
\text { repellent }\end{array}$ & 27.9 & 0 & 50 \\
\hline
\end{tabular}

Calculation of stress parameter $\left(\tan \phi^{b}\right.$ or $\left.\chi\right)$ values for results in tables 1 and 2 would not be appropriate due to the sparsity of data $[22,23]$. However, it is noteworthy that both [7] and [21] found reductions in $\phi^{\prime}$ in $d r y$ materials. This suggests that the silanisation process resulted in a reduction in interparticle friction, likely due to particle coatings reducing surface roughness.

\subsection{Infiltration and slope stability}

Reduction in soil suction and shear strength due to water repellency increases the risk of slope instability. Although examples discussed so far have involved the use of artificially-prepared water repellent soils, excessive drying, for example during summer periods in arid regions, can also lead to the development of water repellent properties on a wide scale. An extreme case is in the event of wildfires, where soil surface temperatures can reach upwards of $300^{\circ} \mathrm{C}$. In addition to drying, wildfires also induce water repellency through infiltration 
of vaporised organic substances (e.g. plant oils and waxes) and the introduction of ash to the upper soil layers [1]. Regions that are affected by wildfires are also generally threatened by post-summer rainy seasons. There is therefore a significant risk of slope instability due to changes in infiltration behaviour [24]. Effects of changes in water repellency on slope stability may also be of concern for deposition processes of treated material, for example mine tailings.

Slope stability and debris flow mechanisms in slopes of varying degrees of water repellency were investigated by [25]. Slope models were prepared by mixing hydrophilic and water repellent sand $\left(d_{50}=0.13 \mathrm{~mm}\right)$ in known ratios from 0 to $100 \%$, in $10 \%$ increments, creating soils of heterogeneous wettability. Water repellent sand was prepared via silanisation, as per $[16,18]$. Results are shown schematically in Figure 4. (a)

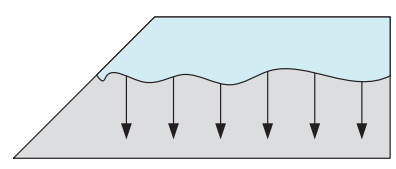

(b)

$\Delta \Delta \Delta \Delta \Delta \Delta \Delta \Delta \Delta \Delta \Delta \Delta \Delta \Delta$

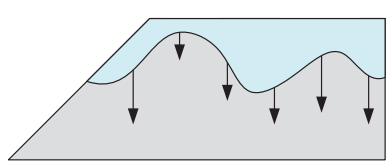

(c) $\quad \Delta \Delta \Delta \Delta \Delta \Delta \Delta \Delta \Delta \Delta \Delta \Delta \Delta \Delta$

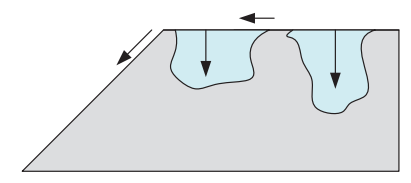

(d) $\quad \Delta \Delta \Delta \Delta \Delta \Delta \Delta \Delta \Delta \Delta \Delta \Delta \Delta \Delta$

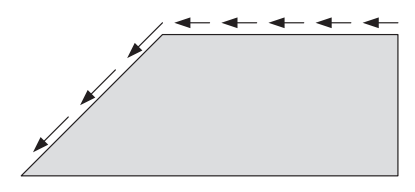

Figure 4. Rainfall infiltration in [25] as affected by water repellency: a) hydrophilic soil (parallel wetting front); b) marginally water repellent (fingered flow); c) severely water repellent (fingered and surface flow); d) fully water repellent (surface flow).

For hydrophilic soil (Figure 4a, water repellent soil content $<10 \%$ ), infiltration produced a wetting front parallel to the infiltration surface. Slope failure was due to a series of retrogressive slumps due to a build-up of pore water pressure at the slope toe. Introduction of water repellent material (Figures $4 \mathrm{~b}$ and $\mathrm{c}$ ) produced a "fingered" flow regime. Fingered flow is a welldocumented phenomenon in water repellent soils and is characterised by an unstable wetting front, with infiltration following paths of least resistance (here, paths of less water repellent material) [26]. Transition to a fingered flow regime occurred for soils with 10 to $60 \%$ water repellent soil content by mass. Slope failure under these conditions was due to a combination of slumping and debris flow via surface erosion. For models with $70 \%$ water repellent material and above, no infiltration was recorded and slope failure was due to erosion only (Figure 4d).

It is important to note that, although tests in [25] used a permanently water repellent soil, water repellency in natural materials varies over time as a function of water content and water exposure (i.e., prolonged wet periods may break down water repellent surface coatings) [27]. An initially-water repellent soil may therefore become more hydrophilic as water contents increase, for example with changing seasons [4]. This is an important consideration for the geotechnical engineer, as different stability conditions must be considered depending on the time of year. A further point of consideration is that all results discussed here are for granular soils. Although the majority of soils affected by water repellency are granular (due to their smaller specific surface areas, e.g. [2]), how the presence of fine particles affects material properties is a necessary question for further research. Indeed, it is common practice in agriculture to add clay to a water repellent soil to increase its water storage capacity [1].

\section{Methods to quantify soil water repellency}

Water repellency has been shown to significantly affect unsaturated soil behaviour. Therefore, it is useful to be able to quantify the degree of water repellency for a given material. The following methods may be useful for geotechnical laboratory or field applications. It is neither the intention here to provide the full procedures for each method, nor to provide an exhaustive list; rather, these methods are listed to demonstrate a range of techniques that can easily be applied in laboratory or field applications.

\subsection{Sessile Drop Method (SDM)}

The SDM is suitable for all likely apparent contact angles $\left(\theta^{*}\right.$, between 0 and $\left.180^{\circ}\right)$ and is performed on the material fine fraction (particles $<250 \mu \mathrm{m}$ ). Contact angles are "apparent" as the test is performed on multiple soil grains, rather than individually, and so values are affected by surface roughness, entrapped air and material water content (due to changes in the soil surface's affinity for water) [29].

Soil particles are tamped onto a glass slide, covered on one side with double-sided adhesive tape. A deionised water droplet of roughly $1 \mu \mathrm{L}$ is then placed on the surface and images of the droplet and surface captured over a required time interval (typical times are 1,2 and 5 seconds). $\theta^{*}$ is the instantaneous angle between the droplet and the soil surface at the droplet extremities at that specific time, as shown in Figure $5[13,28]$.

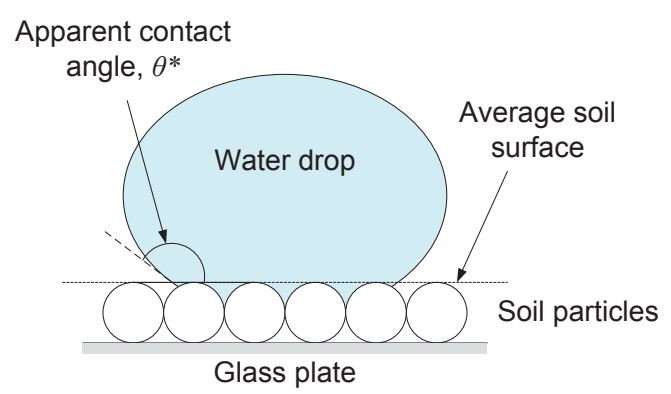

Figure 5. Apparent contact angle measurement using the sessile drop method. 


\subsection{Capillary Rise Method (CRM)}

The CRM is suitable for soils with likely apparent contact angles $\theta^{*}<90$ degrees. Modifications to the CRM are available for $\theta^{*}>90^{\circ}$ [28].

A capillary tube of known height and diameter (typical values are $60 \mathrm{~mm}$ and $9 \mathrm{~mm}$ respectively) and with a sintered glass base is filled with soil under the required conditions to the desired density. A water reservoir is then slowly lifted until it is in contact with the capillary tube and any mass change, $w$, due to capillary uptake recorded. $\theta^{*}$ is then calculated via the Washburn equation, substituting mass for capillary head:

$$
\cos \theta^{*}=\frac{\eta w^{2}}{\rho^{2} \gamma c t}
$$

where $\eta$ is dynamic viscosity, $\rho$ is the density of water, $t$ is time (of capillary rise) and $c$ is a soil-specific factor [28].

\subsection{Water Drop Penetration Time Test (WDPT)}

The WPDT is an index test that provides a rough assessment of water repellency for bulk samples $[25,28]$. A sample of roughly $100 \mathrm{~g}$ (particle size $<2 \mathrm{~mm}$ ) is prepared at the desired water content and density. Water droplets $>1 \mu \mathrm{L}$ are then placed onto a smoothed sample surface at random locations and the time for the drops to infiltrate the sample recorded. Little guidance is provided as to sample dimensions. However, [17] used cylindrical samples of height $10 \mathrm{~mm}$ and $54 \mathrm{~mm}$ diameter. It is suggested here that droplets are not placed closer than $r / 2$ from the sample edge, where $r$ is the sample radius.

Relationships between penetration time and soil wettability are given in Table 3 , based on results in $[30,31]$. Equivalent $\theta^{*}$ for sand, loam and silt loam are also given, as found by [17] using the SDM for artificially hydrophobised (again via silanisation) material tested at different water contents. $\theta^{*}$ are not given as exact equivalents, merely as a method to relate WPDT results to likely soil properties.

Table 3. WDPT soil wettability versus penetration time [31]. Equivalent $\theta^{*}$ from [17]. ${ }^{\text {a }}$ very broad range as $\theta^{*}$ increases rapidly in sand with slight decreases in water content.

\begin{tabular}{|c|c|c|c|c|}
\hline \multirow{2}{*}{$\begin{array}{c}\text { Penetration } \\
\text { time (s) }\end{array}$} & \multirow{2}{*}{$\begin{array}{c}\text { Water } \\
\text { repellency }\end{array}$} & \multicolumn{2}{|c|}{ Equivalent $\theta^{*}$ (degrees) } \\
\cline { 3 - 5 } & Sand & Loam & $\begin{array}{c}\text { Silt } \\
\text { loam }\end{array}$ \\
\hline$<5$ & Hydrophilic & 0 & $0-20$ & $0-20$ \\
\hline $6-60$ & Slight & $0-80^{\mathrm{a}}$ & $20-100$ & $20-60$ \\
\hline $60-600$ & Moderate & $80-$ & $100-$ & $60-120$ \\
\hline $600-3600$ & Severe & 110 & 120 & \\
\hline$>3600$ & Extreme & $>110$ & $>120$ & $>130$ \\
\hline
\end{tabular}

\subsection{Equivalent Cross Section (ECS)}

The ECS is a method for testing water repellency in the field, based on the phenomenon of fingered flow. ECS quantifies the degree of preferential flow in a soil profile according to the area occupied by preferential pathways through a layer of soil of uniform depth. ECS is defined as the minimum fractional area responsible for $90 \%$ of the total flow through the profile. Example flow conditions for a hydrophilic and water repellent soil are shown in Figure 6.

(a)

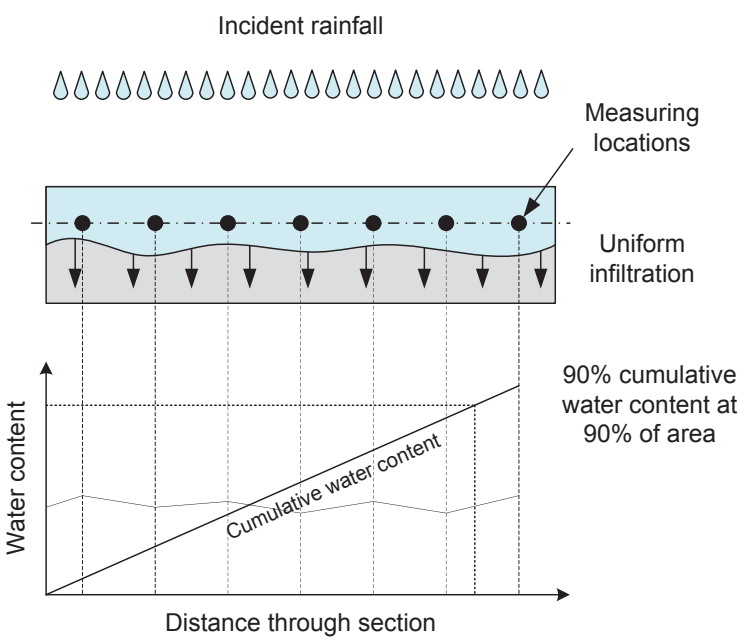

(b)

Incident rainfall

\section{$\Delta \Delta \Delta \Delta \Delta \Delta \Delta \Delta \Delta \Delta \Delta \Delta \Delta \Delta \Delta \Delta \Delta \Delta \Delta \Delta \Delta \Delta \Delta \Delta$}

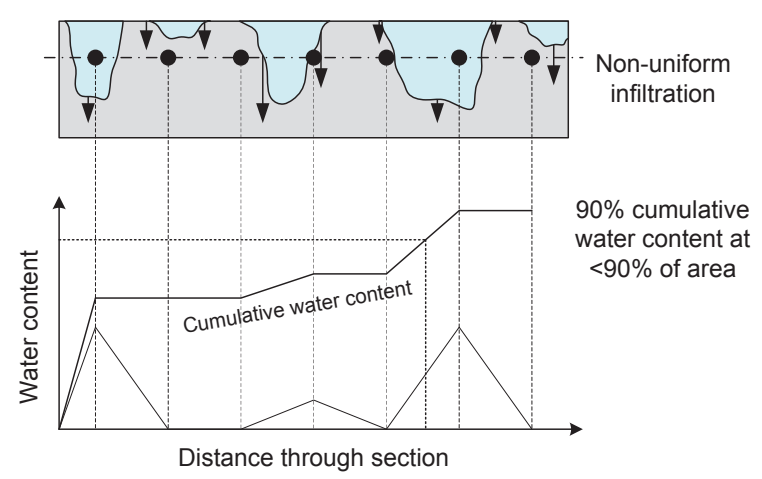

Figure 6. Flow through an instrumented soil profile: a) hydrophilic soil, uniform water content across the section during infiltration; b) water repellent soil, fingered flow and non-uniform water content across the section.

ECS assumes that water content is monitored at uniformly-spaced positions, so that each measurement is representative of flow through the same area. Flow in a given time at a point $x$ during a rainfall event is defined as the change in water content between the minimum and peak value over the duration of the flow, $W_{x}$. Fractional contribution to total flow per point is then given by

$$
f_{x, z}=\frac{W_{x}}{\sum_{x=1}^{n} W_{x}}
$$

where $n$ is the number of measurements (i.e. the number of sensors). $f_{x, z}$ values are then sorted from highest to 
lowest to determine points most responsible for flow. Cumulative flow is then given by $\sum_{1}^{m} f_{x, z}, 1 \leq m \leq n$ For uniform flow, $90 \%$ of the monitored area will be responsible for $90 \%$ of the flow (Figure 6a). As water repellency increases, fractional area responsible for total flow reduces (Figure 6b). ECS can therefore be used to determine changes in water repellency over a given period, which may be important when assessing likely material behaviour or stability, as previously discussed.

\section{Conclusions}

The study of water repellency has been the domain of soil scientists for over a century. However, implications of water repellence on soil behaviour are now becoming recognised by geotechnical engineers. The purpose of this paper was to show how water repellent soil properties can be interpreted using an unsaturated soil mechanics framework.

This paper discussed how water repellence affects the properties of unsaturated soils on a micro and a macro scale. Results from literature investigations were used to demonstrate that differences between the two material conditions are significant. Implications of these behavioural changes were then examined for the cases of soil shear strength (in dry and unsaturated cases) and slope stability, as affected by changes in infiltration patterns. Finally, several methods by which water repellence can be quantified were presented for use in the laboratory and in the field.

\section{Acknowledgements}

The first author is supported by ARC Linkage Grant LP140100375, AMIRA P1087 Integrated Tailings Management Project, funded through AMIRA International by Anglo American, Freeport-McMoRan, Gold Fields, Total E\&P Canada, Newmont, Shell Canada Energy, BASF, Nalco and Outotec, and MRIWA M430 Integrated Tailings Management. The first author would like to thank Margaret Roper and Phil Ward at the WA CSIRO and Daniel Murphy and Ken Flower at UWA for their comments on this work.

\section{References}

1. DeBano, L.F. Journal of Hydrology 231-232, 4-32 (2000).

2. GRDC

https://www.grdc.com.au/Resources/Publications/2014/ 07/Combatting-non-wetting-soils. (2014)

3. Travis, M.J., Weisbrod, N., Gross, A. Science of the Total Environment, 394, 68-74 (2008).

4. Rye, C.F., Smettem, K.R.J. Vadose Zone Journal, 13, 4, 1-12 (2015).

5. Blackwell, P.S. Journal of Hydrology, 231-232, 384395 (2000).

6. Lourenço, S.D.N., Woche, S.K., Bachmann, J., Saulick, Y. Géotechnique Letters, 5, 173-177 (2015).
7. Byun, Y.-H., Tran, M.K., Yun, T.S., Lee, J.-S. Geotechnical Testing Journal, 35, 1, 1-8.

8. Bardet, J.-P., Jesmani, M., Jabbari, N. Géotechnique, 64, 5, 341-350 (2014).

9. Rahardjo, H., Harnas, F.R., Indrawan, I.G.B. et al. Urban Forestry and Urban Greening, 13, 2, 355-364 (2014)

10. Eab, K.H., Likilersuang, S., Takahashi, A. Soils and Foundations, 55, 5, 1270-1281 (2015).

11. DeJong, J., Tibbett, M., Fourie, A.B. Environmental Earth Sciences, 73, 1067-1082 (2015)

12. Atkins, P., De Paula, J. Physical Chemistry, Oxford University Press (2006)

13. Lourenço, S.D.N., Gallipoli, D., Augarde, C.E., Toll, D.G., Fisher, P.C., Congreve, A. Géotechnique, 62, 3, 193-199 (2012).

14. Emerson, W.W., Bond, R. D. Australian Journal of Soil Research, 1, 1, 9-16 (1964).

15. Likos, W. and $\mathrm{Lu}, \mathrm{N}$. Journal of Engineering Mechanics, 130, 646-655 (2004).

16. Czachor, H., Doerr, S.H., Lichner, L. Journal of Hydrology, 380, 104-111 (2010).

17. Liu, H., Ju, Z., Bachmann, J., Horton, R., Ren, T., Soil Science Society of America Journal, 76, 342-349 (2012).

18. Lourenço, S.D.N., Jones, N., Morley, C., Doerr, S.H., Bryant, R. Vadose Zone Journal. DOI: 10.2136/vzj2014.07.0088.

19. Beckett, C.T.S., Augarde, C.E. Canadian Geotechnical Journal, 50, 4, 435-450 (2013).

20. Tarantino, A., Tombolato, S. Géotechnique, 55, 4, $307-$ 317 (2005).

21. Kim, B.S., Takeshita, Y., Kato, S., Park, S.W. Unsaturated Soils: Research and Applications, 1, 159165 (2014).

22. Fredlund, D.G., Morgenstern, N.R., Widger, R.A., Canadian Geotechnical Journal, 15, 3, 313-321 (1978).

23. Khalili, N., Khabbaz, M.H., Géotechnique, 48, 6, 681687 (1998).

24. Suradi, M., Fourie, A.B., Beckett, C.T.S., Buzzi, O. Unsaturated Soils: Research and Applications, 2, 14591464 (2014).

25. Lourenço, S.D.N., Wang, G.-H., Kamai, T. Engineering Geology, 196, 47-58 (2015).

26. Bauters, T.W.J., DiCarlo, D.A., Steenhuis, T.S., Parlange, J.-Y. Soil Science Society of America Journal, 62, 1185-1190.

27. Wijewardana, Y.N.S., Kawamoto, K., Komatsu, T., Hamamoto, S., Subedi, S., Moldrup, P. Unsaturated Soils: Research and Applications, 1, 255-260 (2014).

28. Bachmann, J., Woche, S.K., Goebel, M.-O., Kirkham, M.B., Horton, R. Water Resources Research, 39, 12, SBH11-1-14 (2003).

29. Cassie, A.B.D., Baxter, S. Transactions of the Faraday Society, 40, 546-551 (1944).

30. Dekker, L.W., Ritsema, C.J. Water Resources Research, 30, 9, 2507-2517 (1994).

31. Doerr, S.H., Shakesny, R. A., Dekker, L.W., Ritsema, C.J. European Journal of Soil Science, 57, 741-754 (2006). 